\title{
Alcohol Selectively Attenuates Stress-Induced c-fos Expression in Rat Hippocampus
}

\author{
Andrey E. Ryabinin, ${ }^{1,2}$ Kathleen R. Melia, ${ }^{1}$ Maury Cole, ${ }^{1}$ Floyd E. Bloom, ${ }^{1}$ and Michael C. Wilson' \\ 'Department of Neuropharmacology, The Scripps Research Institute, La Jolla, California 92037 and ${ }^{2}$ Institute of Normal \\ Physiology, Russian Academy of Medical Sciences, Moscow 103009, Russia
}

\begin{abstract}
The ability of ethyl alcohol to modify responses to stress has been well documented (cf. Pohorecky, 1990). However, the structural substrate mediating these effects of alcohol remains undefined. Using immediate early gene (IEG) expression in the brain as a marker of altered neuronal response, we investigated the effect of acute alcohol exposure on the activity of brain regions of rats exposed to $15 \mathrm{~min}$ of restraint stress. Immunocytochemical localization c-Fos protein demonstrated that restraint stress led to an induction of c-Fos expression in several brain structures including cingulate and piriform cortex, cortico-amygdaloid and hippocampo-amygdaloid transition zones, hippocampus, hypothalamus, supramammillary nucleus, and centromedial nucleus of thalamus. An intraperitoneal injection of $2 \mathrm{~g} / \mathrm{kg}$ alcohol prior to stress decreased c-Fos expression in several but not all of these structures. In particular, alcohol strongly attenuated the stress-induced expression of c-Fos in hippocampus and cingulate cortex. Using slot-blot hybridization, significant induction of c-fos mRNA after restraint stress was demonstrated both in hippocampus and cortex, but prior alcohol exposure specifically attenuated c-fos induction only in the hippocampus. The response of c-fos mRNA expression to stress and alcohol differed from the effects on jun-B, c-jun and jun-D mRNA levels. Perhaps surprisingly, acute exposure to alcohol in otherwise unstressed rats did not induce significant changes in expression of IEGs in comparison to control (saline-injected) animals even with doses sufficient to elevate plasma corticosterone. In summary, these studies demonstrate a selective sensitivity of stress-induced activity of neurons of hippocampus and cingulate cortex to acute alcohol exposure.
\end{abstract}

[Key words: immediate early genes, c-fos, restraint stress, alcohol, hippocampus, corticosterone]

Alcohol has a dual effect on the response to stress: on the one hand, exposure is stressful as is shown by the elevation of peripheral corticosterone levels (Ellis et al., 1966), while on the

\footnotetext{
Received Apr. 7, 1994; revised June 16, 1994; accepted July 13, 1994.

We thank Drs. Peter Wilce, Konstantin V. Anokhin, and Inna Y. Shamakina for ideas inspiring this study, Richard Schroeder, for performing corticosterone assays, and Dr. George Koob for the use of facilities. This work was supported by NIAAA-Narcology Center Exchange Program, NARSAD, the MacArthur Foundation, and NIH Grant AA 06420.

Correspondence should be addressed to M. C. Wilson, Ph.D., Department of Neuropharmacology, CVN9, The Scripps Research Institute, 10666 North Torrey Pines Road, La Jolla, CA 92037.

Copyright (C) 1995 Society for Neuroscience 0270-6474/95/150721-10\$05.00/0
}

other hand, alcohol has "tension reduction" effects (Conger, 1956) that antagonize stress-induced increases in blood level of corticosterone and catecholamines (Vogel and Deturck, 1983; Patel and Pohorecky, 1988) and produce anxiolytic behavioral responses (Masserman and Yum, 1946; Koob et al., 1984). Although several sites in the CNS have been proposed to participate in the interaction of alcohol with stress responses (Pohorecky, 1990), the primary structures mediating these effects of alcohol remain to be mapped. Recently, assays of immediate early gene (IEG) expression in the brain have been developed as useful tools to localize neural cells reactive to a variety of stimuli both within the normal range of physiological response as well as in neuropathological situations (Sagar et al., 1988; cf. Dragunow et al., 1989; Morgan and Curran, 1991).

The IEG $c$-fos encodes a nuclear protein regulating transcriptional activity of various genes via binding of the AP- 1 promoter sequence (Curran and Franza, 1988; Sheng and Greenbcrg, 1990). Fos-protein alone can not bind the AP-1 site, but prior to binding must form a heterodimer with the product of other IEGs: jun-B, c-jun, or jun-D. In contrast to Fos, proteins of the Junfamily can form AP-1-binding homodimers of only Jun-proteins (Curran and Franza, 1988; Nakabeppu et al., 1988; Zerial, 1989). In normal physiological states, the basal level of IEG expression in the cell is low, but following stimulation, IEG transcription is rapidly and transiently induced through a cascade of second messengers (Krujer et al., 1985; Curran and Morgan, 1987). Such IEG induction has been observed in the CNS after various pharmacological, electrical, and other manipulative stimuli that are also known activate neurons electrophysiologically (Morgan et al., 1987; Saffen et al., 1988; cf. Dragunow et al., 1989). Of particular interest for the present investigation are studies reporting IEG expression in brain following several specific stress paradigms, including restraint stress (Cecatelli et al., 1989; Arnold et al., 1992; Bing et al., 1992; Honkaniemi, 1992, Melia et al., 1994), foot-shock (Campeau et al., 1991), tail-shock (Schreiber et al., 1991), swim stress (Duncan et al., 1993, Melia et al., 1994), or following stress-based learning induced in the shuttle-box (Maleeva et al. 1989), by step-down passive and active avoidance (Anokhin and Ryabinin, 1991, 1993), Y-maze active avoidance (Tischmeyer et al., 1990; Nikolaev et al., 1992), and conditioned fear (Pezzone, 1992; Smith et al., 1992). Pharmacological studies have suggested the importance of excitatory amino acids (Birder and de Groat, 1992), catecholamines (Bing et al., 1991, Stone et al., 1993), and cytokines (Rivest et al., 1992) for stress-mediated c-fos expression in brain.

Because of the dramatic ability of drug-induced seizures to generate an intense IEG response, the pharmacological regulation of seizure-mediated c-fos expression in brain has been more 
Table 1. Presence of c-Fos-positive cells in different regions of rat brain after restraint stress of saline- and alcohol-pretreated animals

A

\begin{tabular}{|c|c|c|c|c|}
\hline & A & B & $\mathrm{C}$ & D \\
\hline \multicolumn{5}{|l|}{ Cortex } \\
\hline Cingulate & - & - & +++ & + \\
\hline Somatosensory & - & - & ++ & +++ \\
\hline Piriform & + & + & +++ & ++ \\
\hline \multicolumn{5}{|l|}{ Hippocampus } \\
\hline CAl & - & - & - & - \\
\hline Septal CA3 & - & - & ++ & - \\
\hline Temporal CA3 & + & - & ++ & + \\
\hline Septal DG & + & - & + & + \\
\hline Temporal DG & - & - & ++ & - \\
\hline \multicolumn{5}{|l|}{ Amygdala } \\
\hline Central nucleus & ++ & ++ & ++ & ++ \\
\hline CAA & + & - & + & + \\
\hline AHA & + & + & ++ & + \\
\hline \multicolumn{5}{|l|}{ Thalamus } \\
\hline Bed nucleus & + & + & + & + \\
\hline PV & ++ & ++ & +++ & +++ \\
\hline $\mathrm{CM}$ & + & + & ++ & + \\
\hline VLG & +++ & +++ & +++ & +++ \\
\hline \multicolumn{5}{|l|}{ Hypothalamus } \\
\hline $\mathrm{AH}$ & + & + & + & + \\
\hline $\mathrm{DM}$ & + & - & + & + \\
\hline $\mathrm{VM}$ & + & - & + & + \\
\hline $\mathrm{PH}$ & & & + & + \\
\hline SuM & + & + & ++ & + \\
\hline \multicolumn{5}{|l|}{ Septum } \\
\hline Lsi & - & - & + & + \\
\hline SFi & - & - & + & + \\
\hline
\end{tabular}

Numbers of c-Fos-positive cells were counted per brain region on every sixth 40 $\mu \mathrm{m}$ coronal brain section and the highest number reached was indicated by a score: undetectable $(-)$, less than $10(+), 10-30(++)$, more than $30(+++)$. Animals $(N=2)$ : A-saline-injected controls, B-alcohol-injected controls, C-saline-injected restraint-stressed, D-alcohol-injected restraint-stressed. Abbreviations: DG-dentate gyrus, CAA-corticoamygdaloid area, AIIA-amygdalohippocampal area, $\mathbf{P V}$ - paraventricular nucleus of thalamus, $\mathrm{CM}$-centromedial nucleus of thalamus, VLG - ventral lateral geniculate nucleus, $\mathrm{AH}$ - anterior hypothalamus, DM --dorsomedial hypothalamus, VM - ventromedial hypothalamus, $\mathrm{PH}$ posterior hypothalamus, SuM - supramammillary nucleus, Lsi-lateral septal nucleus, $\mathrm{SFi}$-septo-fimbrial nucleus.

extensively addressed than that of stress-induced c-fos expression. Thus, in early studies it was shown that c-fos expression after pentylene tetrazole seizures can be blocked by the NMDA antagonist MK-801, diazepam, or phenobarbital (Morgan et al., 1987, Sonnenberg et al., 1989). Moreover, Le et al. (1990) showed that the c-fos mRNA expression in brain induced by pentylene tetrazole seizures could be inhibited by prior exposure to alcohol. Pharmacological analysis of this attenuating effect of alcohol on IEG response indicated that it was mediated through both NMDA- and GABA-dependent processes, but not through kainate or adenosine receptors (Le et al., 1992). These findings suggested that similar mechanisms might mediate "the tensionreducing" effects of alcohol on stress responses. However, despite its clinical importance, the effect of alcohol on more physiologically relevant stress-induced patterns of neural activity using IEG expression has not yet been addressed.

In the present investigation, we studied the effect of restraint stress (as a primarily psychological stressor) on IEG expression in the brain of alcohol- or saline-pretreated rats. The neuronal populations exhibiting stress-induced c-Fos protein expression were localized by immunohistochemistry. Levels of c-fos mRNA in cortex and hippocampus were statistically compared using slot-blot analysis. To address whether changes in c-fos mRNA expression could affect possible Fos-Jun heterodimer formation, expression of $\mathrm{c}-j u n, j u n-\mathrm{B}$, and $j u n-\mathrm{D}$ was studicd in parallel with c-fos RNA levels. Our results show that alcohol attenuates restraint stress-induced IEG expression in particular populations of neurons including hippocampus. However, although alcohol can induce circulating levels of corticosterone in otherwise unstressed subjects, alcohol treatment alone does not affect basal IEG expression in hippocampus or cortex.

\section{Materials and Methods}

Animals. Adult male Sprague-Dawley rats (Charles River Laboratories), weighing 240-260 gm at the onset of each experiment, were used. Animals were housed two per cage in Plexiglas cages $(45 \times 22 \times 20 \mathrm{~cm})$ with sawdust bedding in a colony room kept at $22^{\circ} \mathrm{C}$ on a $12: 12 \mathrm{hr}$ light: dark cycle (lights on at $0600 \mathrm{hr}$ ) with ad libitum access to food and water throughout each experiment. Animals of different groups were kept in separate cages. For 1 weck prior to each experiment, animals received daily intraperitoneal injections of $0.9 \%$ saline $(0.3 \mathrm{ml})$ to $\mathrm{fa}-$ cilitate adaptation to injection and handling procedure.

Experimental procedures. All animal manipulations were conducted between 0700 and $1100 \mathrm{hr}$. Animals received intraperitoneal injection of $16 \%$ (weight/volume) alcohol in $0.9 \%$ saline or an equal volume of $0.9 \%$ saline. In the experiments addressing alcohol effects on stressinduced c-fos expression, $10 \mathrm{~min}$ after injections restraint stress was imposed by placing the animals in hemicylindrical $(20.5 \times 9 \times 6 \mathrm{~cm})$, well-ventilated Plexiglas tubes for $15 \mathrm{~min}$. During this stress procedure, animals were able to turn around easily within the tubes but were not able to walk. Animals were sacrificed for RNA analysis $1 \mathrm{hr}$ after injection by decapitation and for protein analysis $2 \mathrm{hr}$ after injection by chloral hydrate narcosis and intracardial perfusion. In the time between injections, restraint stress, and sacrifice, rats were returned to their home cages. Blood alcohol levels were determined in trunk blood collected immediately after decapitation. Samples were centrifuged, supernatant was removed and stored at $-70^{\circ} \mathrm{C}$. Samples $(50 \mu \mathrm{l})$ of plasma were assayed for alcohol at $340 \mathrm{~nm}$ using a Sigma (St. Louis, MO) NAD$\Lambda \mathrm{DH}$ kit.

Corticosterone assay. Ten microliters of plasma was used for determination of corticosterone levels by radioimmunoassay (ICN Biochemical, Costa Mesa, CA).

Immunohistochemical analysis. Five minutes after chloral hydrate narcosis $(350 \mathrm{mg} / \mathrm{kg}$, i.p.) rats were quickly perfused with $0.9 \%$ saline followed by $2 \%$ paraformaldehyde in isotonic sodium phosphate buffer (PBS), pH 7.4. Brains were dissected, fixed in the perfusion buffer for $2 \mathrm{hr}$, and stored for $3-7 \mathrm{~d}$ in $20 \%$ sucrose/PBS. Sections $(40 \mu \mathrm{m})$ were cut on a Cryocut 1800 (Leica, Foster City, CA) and collected in PBS. Immunohistochemistry for c-Fos protein was performed with affinity purified rabbit polyclonal antibodies raised against a peptide corresponding to human c-Fos amino acid residues 3-16 (Santa Cruz Biotechnology, Santa Cruz, CA) that is not reactive to fos-B and fra-1 proteins. The immunoreaction was detected with Vectastain $A B C$ kit (Vector Laboratory Inc., Burlingame, CA), according to the following procedure. Sections were incubated with goat anti-rabbit blocking serum in $0.3 \%$ Triton X-100/PBS solution for $2 \mathrm{hr}$ at room temperature followed by anti-c-Fos serum (dilution $1: 1000$ ) in $0.3 \%$ Triton X-100/ $0.1 \%$ bovine serum albumin (BSA)/PBS for $20 \mathrm{hr}$ at $4^{\circ} \mathrm{C}$. Sections were then rinsed with PBS, incubated with secondary biotinylated antibody $\left(50 \mu \mathrm{l}\right.$ in $10 \mathrm{ml}$ of $0.3 \%$ Triton X-100/PBS) for $1 \mathrm{hr}$ at $23^{\circ} \mathrm{C}$, rinsed with PBS, incubated for $1 \mathrm{hr}$ with the $\mathrm{ABC}$ reagent $(100 \mu \mathrm{l}$ of reagent $\mathrm{A}$ and $100 \mu \mathrm{l}$ of reagent $\mathrm{B}$ in $10 \mathrm{ml}$ of $0.3 \%$ Triton X-100/PBS), and rinsed again with PBS. Enzymatic development was done in $0.05 \%$ DAB in $0.5 \times$ sodium phosphate buffer containing $0.003 \%$ hydrogen peroxide for $7 \mathrm{~min}$. After rinsing in PBS, sections were mounted on gelatin-coated glass slides. For a background control, sections were incubated without the primary antibody. To confirm that the immunocytochemical detection was not limiting, some sections were also incubated with twoand eightfold higher c-Fos antibody concentrations. Cell counting was performed manually at $100 \times$ magnification; questionable cells were checked for nuclear localization of staining using magnification of $400 \times$. 
RNA isolation and analysis. After decapitation, cortex and hippocampus were quickly dissected, frozen on dry ice, and stored at $-70^{\circ} \mathrm{C}$. Total RNA was isolated from brain structures of individual animals using the guanidine-isothiocyanate/phenol method (Chomczynski and Sacchi, 1987). RNA was dissolved in sterile distilled water, quantified by spectrophotometry at $260 \mathrm{~nm}$ and stored at $-70^{\circ} \mathrm{C}$. For quantitative measurements of mRNA levels, slot-blots of hippocampal and cortex RNA prepared from individual animals were performed on 1, 2, and 4 $\mu \mathrm{g}$ samples of total RNA to access the linearity of the hybridization signal. The RNA samples were denatured in 50\% formamide, $10 \times$ SSC at $65^{\circ} \mathrm{C}$ and loaded onto Nytran nylon membranes using Schleicher and Schuell (Keene, NH) Manifold II slot-blot system, washed with $10 \times$ SSC and UV cross-linked using GS-Gene Linker (Bio-Rad, Hercules, CA). Replicate filters for hippocampus and cortex of each experiment were prepared and analyzed.

cDNA probes for rat c-fos (gift from T. Curran, Roche Institute), cyclophilin (gift from P. E. Danielson, The Scripps Research Institute), c-jun, jun-B, and jun-D (from ATCC) were used in this study. Probes were labeled by ${ }^{32} \mathrm{P}-\mathrm{dCTP}$ and ${ }^{32} \mathrm{P}-\mathrm{dATP}$ (Amersham, Arlington Heights, IL) using a Decaprime kit (Ambion Inc., Austin, TX). The specificity of the probes was initially determined by Northern Blot hybridization. Slot-blot or Northern blot filters were prehybridized overnight at $42^{\circ} \mathrm{C}$ in hybridization buffer $(50 \%(\mathrm{v} / \mathrm{v})$ formamide, $2 \times$ Denhardt's solution, $0.5 \%$ SDS, $1 \mathrm{~mm}$ sodium pyrophosphate, $200 \mu \mathrm{g} / \mathrm{ml}$ denatured salmon sperm DNA and $200 \mu \mathrm{g} / \mathrm{ml}$ denatured yeast tRNA), and then hybridized with approximately $2 \mathrm{ng} / \mathrm{ml}$ of the labeled probe in hybridization buffer for $24 \mathrm{hr}$ at $42^{\circ} \mathrm{C}$. Filters were washed in $0.5 \times \mathrm{SSC}, 0.1 \% \mathrm{SDS}, 1 \mathrm{~mm}$ sodium pyrophosphate at $37^{\circ} \mathrm{C}, 56^{\circ} \mathrm{C}$, and $65^{\circ} \mathrm{C}$ and exposed to Amersham Hyperfilm-MP $x$-ray film. Time of exposure depended on the strength of the signal and was predetermined in a series of preliminary experiments to give bands in a linear range of intensity. Rehybridization of the filter with a new probe was done after eluting previously hybridized probe by boiling the filter in $0.1 \times$ SSC, $0.1 \%$ SDS. Quantitation of band intensities was done by scanning the films with a Microtek (Torrance, CA) Scanmaker 600ZS, digitizing with Microtek BLACK \& WHITE software. Signal intensity was measured in pixels/band using NIH IMAGE 1.43 software. Data on IEG expression were normalized to corresponding cyclophilin values and the two normalized values from 4 and $2 \mu \mathrm{g}$ RNA loading were averaged to obtain levels of IEG mRNA relative to cyclophilin. This value was used as a single data point for statistical analysis (data obtained on $1 \mu \mathrm{g}$ concentration was too low to be quantified).

Statistical analysis. Statistical analysis of the obtained values was done using two-way and one-way factorial ANOVA and the Scheffe $F$ test; for post hoc comparisons $p$ values of less than 0.05 were considered statistically significant.

\section{Results}

Immunohistochemical localization of $c$-Fos expression in rat brain after restraint stress preceded by saline or alcohol injection

Preliminary experiments showcd that cxposurc of unhandled rats to various stress paradigms including restraint, residentintruder, as well as simple saline injections dramatically increased the number of $\mathrm{c}$-fos immunoreactive neurons in hypothalamus, cortex, hippocampus, and other brain regions (data not shown), consistent with reports of other investigators (Giovanelli et al., 1990; Sharp et al., 1991; Covenas et al., 1993; Stone et al., 1993). However, if the animals were previously habiluated to the stress of handling and saline injection, we observed that the amount of c-Fos immunoreactivity was substantially reduced, allowing for the detection of a more specific response, possibly reflecting activation of selected cell populations responding to the particular stressor.

To identify those cell populations exhibiting interactions between alcohol and their response to stress, c-Fos immunoreactivity was compared across the following groups of animals that were first habituated to injection procedures and handling: (1) saline control rats that received a saline injection and were returned to their home cage; (2) alcohol controls that received a $2 \mathrm{~g} / \mathrm{kg}$ alcohol injection and were returned to their home cage; (3) saline/stress animals that received a saline injection, were returned to their home cage for $10 \mathrm{~min}$, then placed into the restraint tube for $15 \mathrm{~min}$, and finally returned to their home cage; and (4) alcohol/stress animals that received a $2 \mathrm{~g} / \mathrm{kg}$ alcohol injection, were returned to their home cage for $10 \mathrm{~min}$, then placed into the restraint tube for $15 \mathrm{~min}$, followed by being returned to their home cage again (two rats per group). All rats were sacrificed $2 \mathrm{hr}$ after injection of either saline or alcohol resulting in a $95 \mathrm{~min}$ interval from the end of the restraint period in groups saline/stress and alcohol/stress. The alcohol dose of 2 $\mathrm{g} / \mathrm{kg}$ was chosen as a commonly used dose exhibiting strong interaction with the effects of behavioral stress without a gross neurotoxic component (cf. Pohorecky, 1990).

Immunohistochemical analysis performed on coronal brain sections corresponding to bregma levels from 0 to $-4.5 \mathrm{~mm}$ revealed a similar pattern of c-Fos expression in both salineand alcohol-injected control rats (Table 1). Fos-positive cells were present in thalamus: in the paraventricular nucleus, the centromedial nucleus, and the ventral lateral geniculate nucleus, in the central nucleus of the amygdala and scattered through various hypothalamic areas. Localization of Fos-positive staining in these regions was specifically nuclear. However, in the paraventricular nucleus of hypothalamus, a substantial part of the staining was extranuclear that probably reflected cross-reactivity of the chosen antibody with cytoplasmic proteins. Consistent with this interpretation, extranuclear immunoreactivity was never observed using other antibodies recognizing both c-Fos and Fos-related antigens (own unpublished observations and Giovanelli et al., 1990). To avoid any misinterpretation of this staining, Fos-immunoreactivity in the paraventricular nucleus of hypothalamus was not further analyzed.

In animals subjected to restraint stress, a clear induction of c-Fos expression was observed, resulting in detection of additional sets of Fos-positive nuclei in cortical, hypothalamic, and hippocampal regions (Fig. 1). Comparison of restrained animals that received either alcohol or saline injections prior to the restraint stress showed major differences in c-fos expression in hippocampus and certain other, but not all, regions of the brain. Thus, in the animals of the saline/stress group, c-Fos-positive cells were abundant in the CA3 region of hippocampus and dentate gyrus (Fig. 1C,E,F). Interestingly, Fos-immunoreactive cells were unevenly distributed in hippocampus; that is, they were substantially more frequent in the temporal pole of hippocampus than in the septal pole. In the animals of the alcohol/ stress group, c-Fos expression was dramatically attenuated such that no positive cells were found in the dentate gyrus of the temporal hippocampus (please compare Fig. $1 C$ and $D$ ) and in the CA3 region (Table 1). The difference in c-Fos expression between alcohol- and saline-injected stressed animals could be also observed in particular regions of the neocortex; that is, c-Fos-expressing cells were more abundant in cingulate cortex and piriform of the animals from the saline/stress group than in the alcohol/stress animals. In contrast, consistently more c-fospositive cells were found in the somatosensory regions of the cortex of alcohol/stress than in saline/stress animals (Table 1). Increasing the amount of primary antibody added to the immunohistochemical reaction did not increase the number of Fos-positive cells detected, but merely increased the background staining, suggesting that the relatively small number of stained cells reflected all cells expressing c-Fos protein and not a limited 

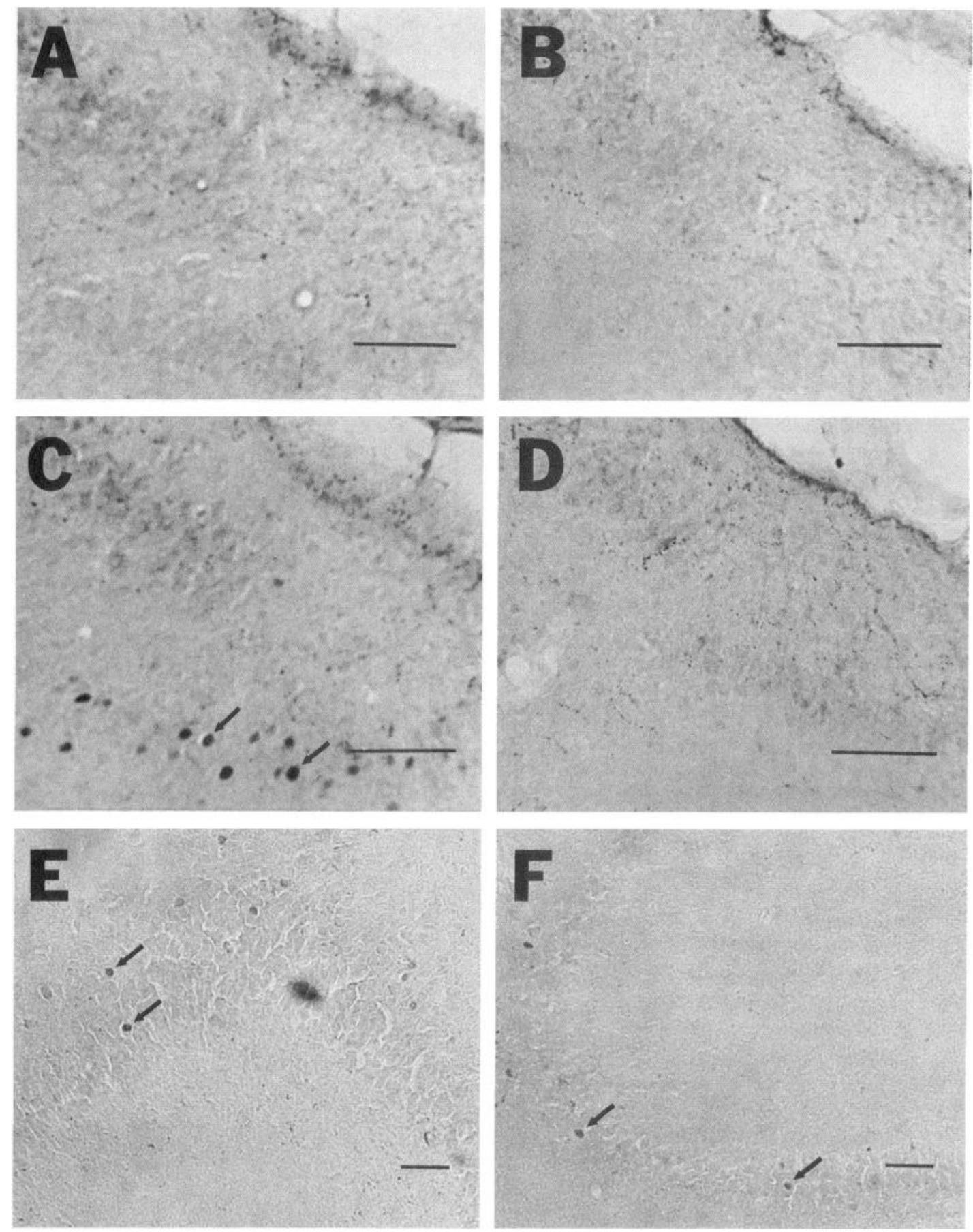

Figure 1. c-Fos protein is induced in hippocampal neurons after restraint stress in saline but not alcohol-pretreated animals. Representative coronal sections of the hippocampus stained immunohistochemically for c-Fos at approximate bregma position $-4.3 \mathrm{~mm}$ are shown. $A-D$ compare the dentate gyrus of the temporal pole of hippocampus of saline-injected control $(A)$, alcohol-injected control $(B)$, saline-injected restraint $(C)$, and alcohol-injected restraint $(D)$ animals. Lower magnification of the edge of the temporal $(E)$ and septal $(F)$ pole of the CA3 pyramidal layer of salineinjected restraint-stressed animals is demonstrated, where the corresponding to $E$ and $F$ areas of alcohol-injected restraint-stressed animals showed no c-Fos-positive staining. Bar indicates $100 \mu \mathrm{m}$. Arrows point to exemplary c-Fos-positive cells.

sensitivity or titer of the antibody. The difficulty of accurately aligning the precise brain regions with relatively small number of Fos-positive cells responding to the specific behavioral stimuli did not allow reliable statistical comparisons of the density of c-Fos-expressing cells between animals of experimental and control groups. To achieve a statistical evaluation of the interaction between alcohol and stress on c-fos expression mRNA levels were quantitatively analyzed in the following experiment.

\section{IEG $m R N A$ levels in rat hippocampus and cortex after restraint stress preceded by saline or alcohol injection}

To investigate the significance of the alcohol effects on c-fos expression mRNA levels of IEG were analyzed by slot-blot hybridization of total RNA isolated from the entire hippocampus and cortex in an independent experiment comprised of the analogous groups of saline and alcohol controls and saline/stress 

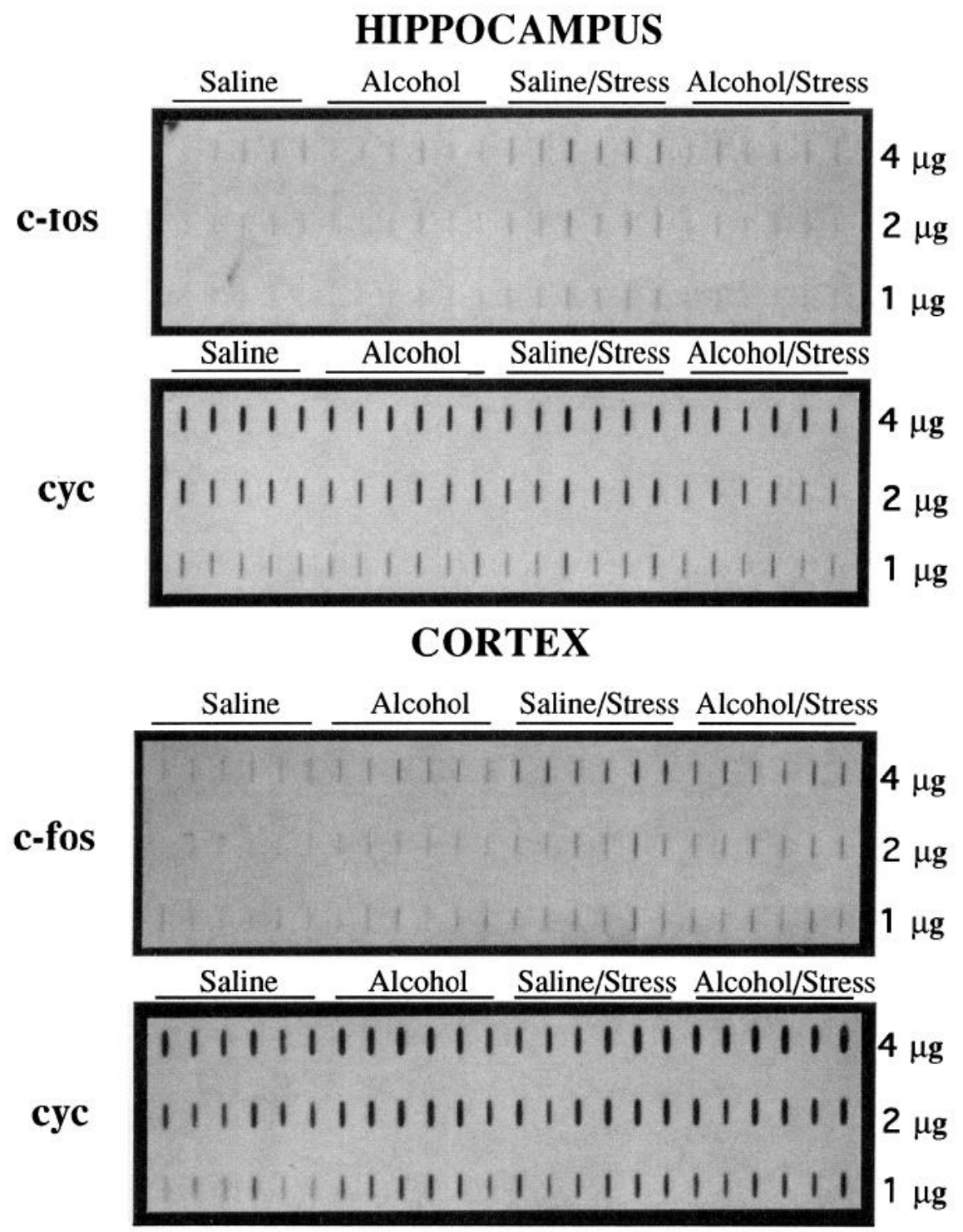

Figure 2. Slot-blots showing the level of c-fos mRNA in hippocampus and cortex of individual rats from experimental groups: saline-injected controls (Saline), alcohol-injected controls ( $\mathrm{Al}$ cohol), saline-injected restraint animals (Saline/Stress), and alcohol-injected restraint animals (Alcohol/Stress); 4,2 , and $1 \mu \mathrm{g}$ indicated on the right show the three different amounts of total RNA from each animal loaded to ascertain the linearity of hybridization. Note that the higher level of c-fos hybridization in animals exposed to restraint alone (Saline/Stress) relative to all other groups is evident in the $1 \mu \mathrm{g}$ lane on the blot with hippocampal but not in cortex RNA samples. $c y c$-result of rehybridization of the same filters with the cyclophilin cDNA to control for loading differences. and alcohol/stress rats (six animals/group) to the described in the previous section. To assay the peak response in c-fos mRNA expression, animals were sacrificed $1 \mathrm{hr}$ after injections (35 min after restraint stress).

Blood alcohol levels (BALs) measured in the trunk blood collected from alcohol animals reached an average of $119 \pm$ 17.1, while BALs in the alcohol/stress group reached an average of $97 \pm 13.1$; control saline and the saline/stress groups had negligible BALs of $1 \pm 0.4$ and $1.5 \pm 0.6$, respectively. As expected, there was a significant effect of alcohol on blood alcohol concentration as confirmed by two-way factorial ANOVA $[F(1,19)=89.2, p<0.0001]$. More importantly, no effects of stress on blood alcohol levels $[F(1,19)=0.92, p=0.35]$ or stress by alcohol interaction $[F(2,19)=1.04, p=0.32]$ were observed, indicating that restraint stress and, therefore, metabolic differences between stressed and unstressed groups did not influence blood alcohol concentration in our experiment.

$c$-fos $m R N A$ expression. As shown in Figure 2 and summarized in Figure $3 A$ and $B$, slot-blot hybridization of the total RNA isolated from hippocampus and cortex of individual animals confirmed the previous immunocytochemical findings that there were no significant effects of alcohol on basal expression of c-fos. As expected, restraint stress significantly increased c-fos expression in both brain structures. However, c-fos induction in hippocampus was significantly lower in restraint-stressed animals pretreated with alcohol than in saline-injected animals subjected to the same stress. In contrast, the expression of c-fos mRNA in cortex of restraint-stressed animals was not significantly affected by alcohol pretreatment. A two-way factorial ANOVA of hippocampal levels of c-fos mRNA showed significant effects of stress $[F(1,19)=17.1, p<0.001]$, alcohol $[F(1.19)$ $=15.8, p<0.001]$ and a significant stress by alcohol interaction $[F(2,19)=13.8, p<0.01]$, reflecting a differential effect of alcohol on c-fos expression in hippocampus of restraint-stressed relative to nonstressed animals. In comparison, two-way factorial ANOVA showed a significant effect of stress in cortex $[F(1,19)=22.4, p<0.001]$, but no significant effects of alcohol $[F(1,19)=2.9, p=0.1]$, and no significant interaction of stress and alcohol $[F(2,19)=1.7, p=0.2]$ on $c$-fos mRNA levels. This suggested that the dramatic attenuation of stress-induced c-fos expression in the cingulate cortex by alcohol was masked by other cortical cells not responsive to alcohol when the entire 

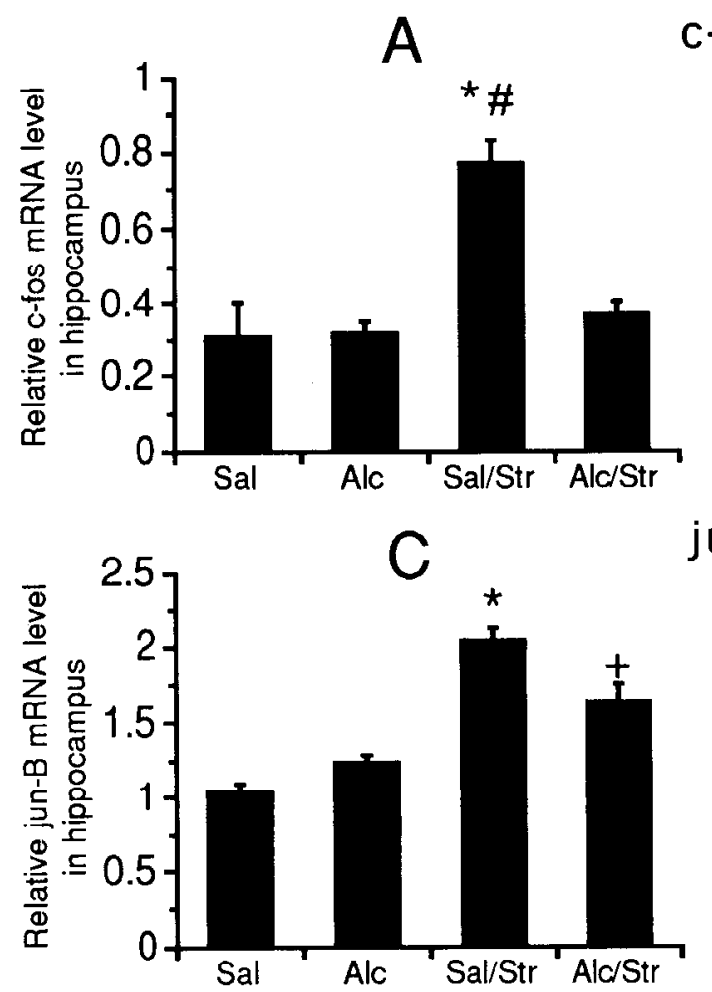

c-fos

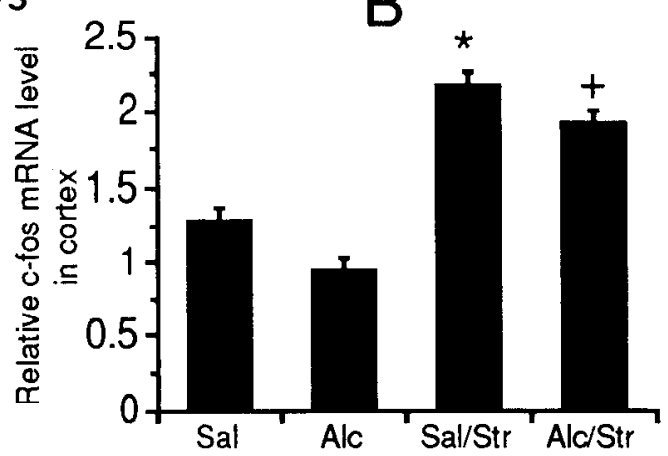

jun-B
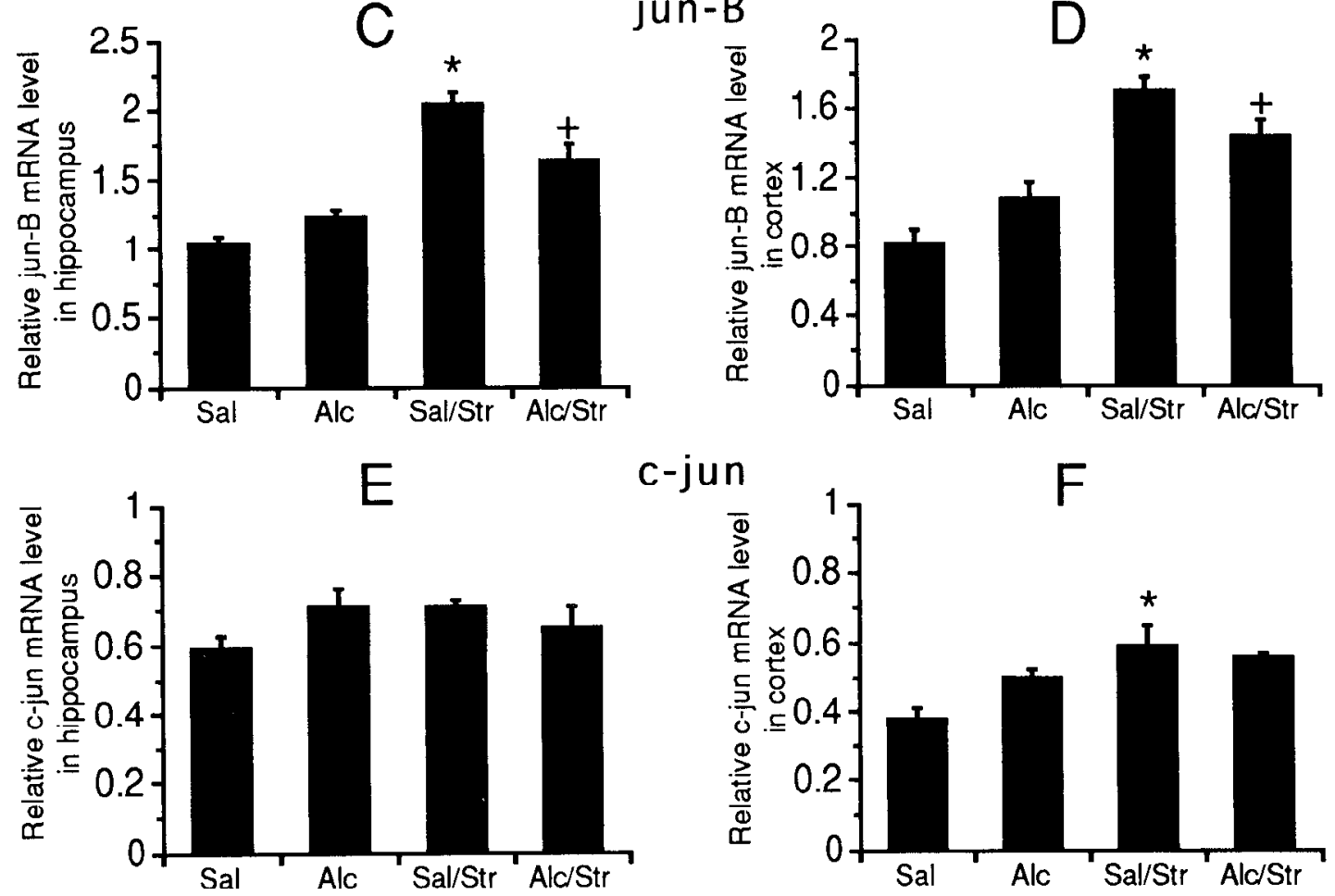

c-jun
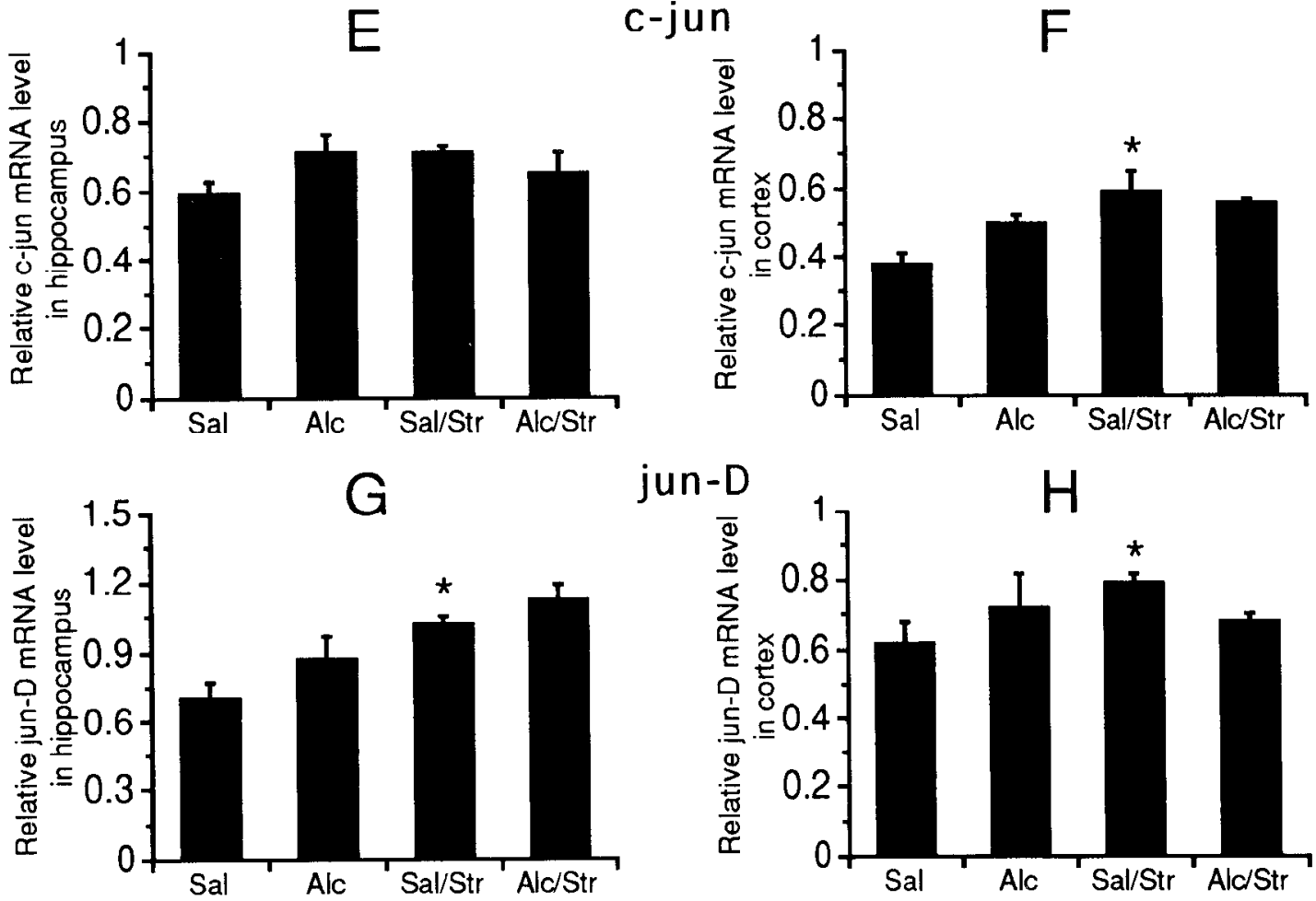

Figure 3. Differential effects of alcohol on restraint stress-induced IEG expression in hippocampus (left) and cortex (right). Densitometric data on IEG mRNA levels were normalized to the level of cyclophilin mRNA and expressed as mean \pm SEM. Groups of animals: Sal-saline-injected controls; $A l c-$ alcohol-injected controls; $S a l / S t r-$ saline-injecled restraint animals; and $A l c / S t r-$ alcohol-injected restraint animals. $N=6$ for all groups of animals, except $N=5$ for hippocampus of Sal. *Significantly different from Sal; +Significantly different from Alc; \#, significantly different from all other groups. $p<0.05$. Note difference in $Y$-axis values for different probes and brain structures. Quantitative comparisons were analyzed only between groups within each histogram since the densitometry signal reflects not only the difference in the level of mRNAs but also the specific activity of the probes and hybridization efficiency. 

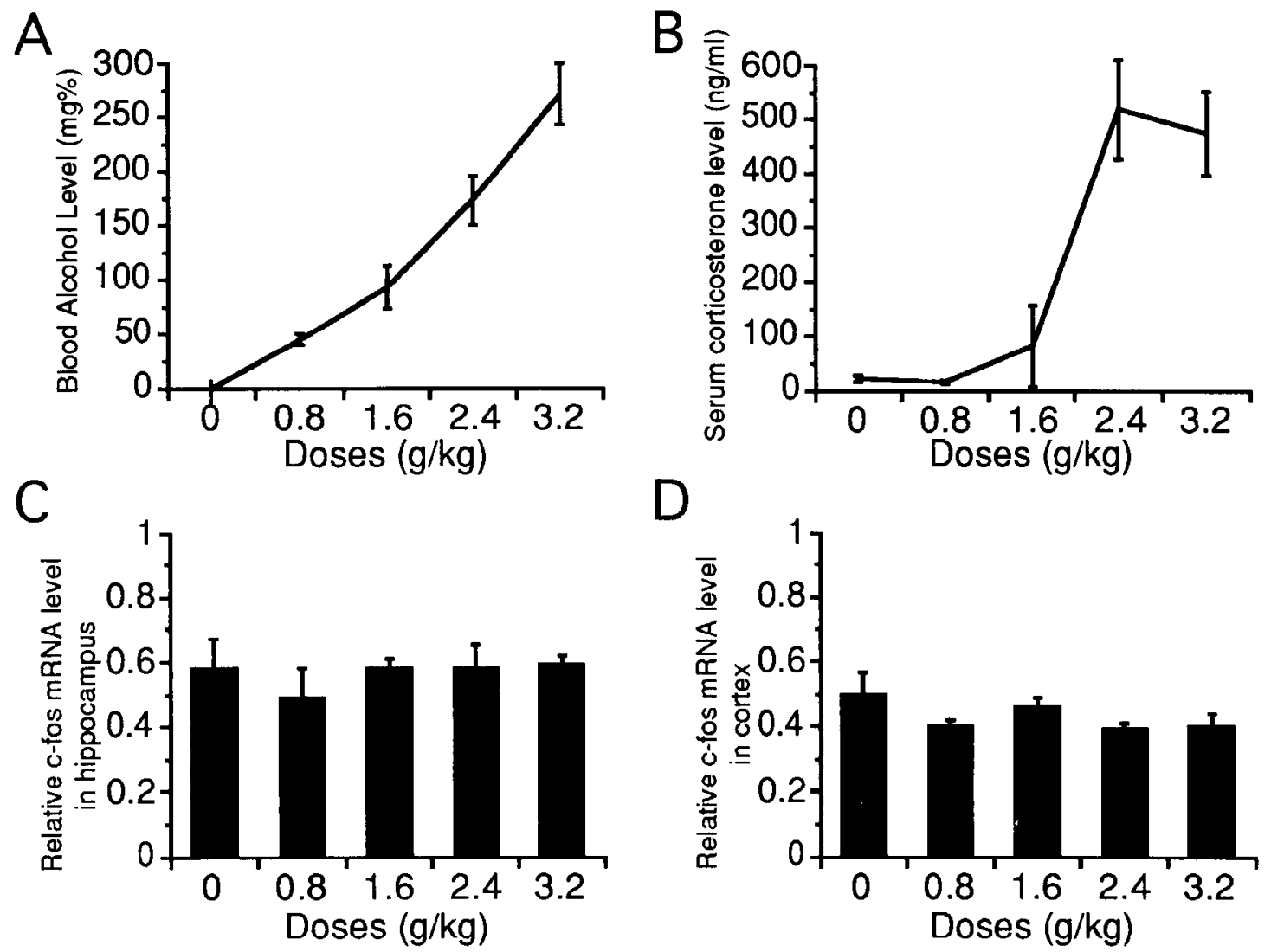

Figure 4. Increasing doses of alcohol lead to corresponding increases in blood alcohol levels, circulating corticosterone, but not c-fos mRNA expression in rat hippocampus and cortex. Rats were exposed to $0.8,1.6,2.4$, and $3.2 \mathrm{~g} / \mathrm{kg}$ alcohol by intraperitoneal injection of $1.5,3,4.5$, and $6 \mathrm{ml}$ of $16 \%$ alcohol $(N=3$ for each dose) or isotonic saline $(1.5,3$, and $6 \mathrm{ml}-$ two for each volume). $A$ shows that the BALs exhibit an expected dose response, $B$ demonstrates that corticosterone response requires $1.6 \mathrm{~g} / \mathrm{ml}$ or higher dose of alcohol. $C$ and $D$ show the normalized data obtained from slot-blot hybridizations of RNA isolated from hippocampus and cortex of individual rats. Densitometric data on c-fos mRNA levels were normalized to the level of cyclophilin mRNA. All data are expressed as mean \pm SEM. As indicated in Figure 3, the quantitative differences were cvaluated only between groups within each histogram.

cortex was assayed. Similar results were obtained in an independent replicate experiment. In a pilot study, reliable differences in c-fos expression in hypothalamus, amygdala, and cerebellum could not be discerned between saline- or alcoholinjected groups exposed to restraint stress.

jun- $B m R N A$ expression. As for c-fos, both in hippocampus and cortex of saline-injected and alcohol-injected control animals, the basal levels of jun-B mRNA were not significantly different, and jun-B mRNA was increased in hippocampus and cortex of acutely stressed animals (Fig. $3 C, D$ ). However, in contrast to $\mathrm{c}-f_{o s}$, alcohol produced only slight attenuation of jun-B expression in both these structures. In hippocampus, a two-way factorial ANOVA revealed a significant effect of stress $[F(1,19)$ $=77.3, p<0.001]$, no significant effects of alcohol $[F(1.19)=$ $1.1, p=0.3]$, but a significant stress by alcohol interaction $[F(2,19)=11.5, p<0.01]$ on jun-B mRNA levels. As found for hippocampus, a two-way factorial ANOVA performed on mRNA levels of cortical RNA showed a significant effect of stress $[F(1,19)=65.5, p<0.001]$, no significant effects of alcohol $[F(1,19)=0.0004, p=0.98]$, and a significant stress by alcohol interaction $[F(2,19)=11.1, p<0.01]$. Thus, expression of $j u n-\mathrm{B}$ mRNA in cortex and hippocampus was induced by restraint stress, whereas alcohol decreased stress-induced levels of jun-B expression. IIowever, according to post hoc analysis, this attenuation was not statistically significant, in contrast to the more robust effect of alcohol on stress-induced c-fos expression in hippocampus.

$c$-jun $m R N A$ expression. Normalized data obtained from slotblot hybridization showed little difference in c-jun expression in hippocampus across all experimental groups (Fig. 3E). Whereas restraint-stressed animals had a higher level of c-jun expression in cortex compared with saline controls, no obvious effect of alcohol on this restraint induced gene expression was observed (Fig. 3F). A two-way factorial ANOVA showed no significant effect of stress $[F(1,19)=0.47, p=0.5]$, alcohol $[F(1,19)=0.42, p=0.52]$, or any stress by alcohol $[F(2,19)=$ $3.3, p=0.09]$ on c-jun mRNA levels in hippocampus. A twoway factorial ANOVA performed on cortical c-jun data did reveal a significant effect of stress $[F(1,19)=13.7, p<0.002]$, no significant effects of alcohol $[F(1,19)=1.3, p=0.26]$, but a significant stress by alcohol interaction $[F(2,19)=15.4, p<$ $0.001]$ on c-jun mRNA levels in cortex. The apparent significance of the stress by alcohol interaction probably reflected the fact that the level of c-jun mRNA expression in the saline controls was lower than in all other groups. This difference, moreover, was not repeated in a duplicate experiment and was not detected in further experiments evaluating alcohol dose effects (see below).

jun- $D m R N A$ expression. The level of jun-D mRNA in hippocampus was significantly higher in restraint-stressed animals 
than in control animals; however, alcohol did not significantly affect the expression of this gene (Fig. 3G). Restraint-stressed animals had also a higher level of jun-D expression in cortex than control animals and this level appeared to be lower in alcohol injected restraint-stressed animals (Fig. $3 H$ ). A two-way factorial ANOVA showed significant effect of stress $[F(1,19)=$ $16.8, p<0.001]$, but no significant effects of alcohol $[F(1,19)$ $=3.4, p=0.08$ ] on jun-D mRNA levels in hippocampus and no significant interaction of stress and alcohol $[F(2,19)=0.24$, $p=0.63]$. A two-way factorial ANOVA performed on cortical data showed no significant effect of stress $[F(1,19)=3.3, p=$ $0.09]$ or alcohol $[F(1,19)=0.003, p=0.96]$, but a significant stress by drug interaction $[F(2,19)=8.7, p=0.008]$ reflecting a lower level of $j u n-\mathrm{D}$ mRNA in alcohol pretreated than in saline-pretrcated animals. However, post hoc analysis revealed that the difference in jun-D expression was only significant between saline control animals and saline/stress rats, again suggesting that $j u n-\mathrm{D}$ expression in cortex after stress was not as sensitive to alcohol as clearly found for $\mathrm{c}-$ fos expression in hippocampus.

These data illustrate that the response of IEGs appears to be differentially affected by stress and alcohol stimuli and that $c$-fos mRNA expression is visibly reactive to restraint stress in both cortex and hippocampus, but sensitive to alcohol only in hippocampus.

\section{Different doses of alcohol do not change basal IEG expression in hippocampus and cortex}

Alcohol is known to exhibit differential effects on behavior and stress responses depending on the dose of the drug (Ellis et al., 1966; Engcl and Liljerquist, 1983). Therefore, although the dose of $2 \mathrm{~g} / \mathrm{kg}$ used in the previous experiments did not change basal IEG expression, it is possible that a different dose of alcohol could reveal changes in neural activity not noticeable in the previous experiments. This question was addressed in a doseresponse experiment where groups of animals received a ethanol doses of $0.8,1.6,2.4$, or $3.2 \mathrm{~g} / \mathrm{kg}$ of alcohol (three animals/ group). Saline control rats received comparable volumes of $0.9 \%$ saline (1.5, 3, and $6 \mathrm{ml}$-two animals per dose). Animals were sacrificed $1 \mathrm{hr}$ after either saline or alcohol injection, hippocampal and cortical brain regions were isolated for RNA analysis, and trunk blood was collected for assaying BALs and the level of corticosterone.

As expected, a one-way factorial ANOVA showed a significant effect of injected dose of alcohol on BALs $[F(4,17)=54.61, p$ $\left.=10^{-4}\right]$ and corticosterone levels $\left[F(4,17)=22.96, p=10^{-4}\right]$ (Fig. 4). A one-way factorial ANOVA showed no significant effect of alcohol on c-fos mRNA levels in hippocampus $[F(4,17)$ $=0.88, p=0.5]$ or in cortex $[F(4,16)=0.22, p=0.93]$ (Fig. 4). Animals injected with different amounts of saline showed no difference in c-fos expression in hippocampus or cortex. jun$\mathrm{B}, \mathrm{c}-j u n$, and jun-D expression was also analyzed and, similarly, no significant changes were found (data not shown).

\section{Discussion}

In general, the results described here confirm previous observations of low basal levels of c-fos expression in the brain of naive animals and its inducibility by stressful behavioral stimuli (Cecatelli et al., 1989; Maleeva et al., 1989; Anokhin and Ryabinin, 1991). Based on studies showing that stress-induced c-fos expression in major brain structures can be downregulated by repeated exposure to the stressor but is readily activated by a novel stimulus (Melia et al., 1994), in the present experiments, animals were first habituated to the otherwise stressful injection and handling procedures. The immunohistochemical data presented demonstrates, in fact, that despite habituation the control groups still exhibited c-Fos expression in several brain regions, particularly in the paraventricular nucleus of thalamus, the ventral lateral geniculate nucleus, and the central nucleus of amygdala. It is not yet clear whether c-Fos expression in these structures reflects true basal activity, perhaps reflecting constant stimulation (i.e., visual) or is a reaction to the relatively large injection of saline or alcohol solutions in experimental animals compared to that during habituation (see Materials and Methods). Whereas the first explanation might account for expression in the paraventricular nucleus of thalamus and the ventral latcral geniculate nucleus, the second explanation seems more plausible for c-Fos expression in the central nucleus of amygdala since c-Fos has been shown to be induced in this brain region by stress (Honkaniemi, 1992). In contrast to these areas, control animals had a sparse density of Fos-immunoreactive cells in the other structures where $c$-Fos expression, including the hypothalamus, the amygdaloid complex, the thalamus, the hippocampus, and cortex. In response to restraint stress, certain subregions through these brain structures demonstrated a different extent of induction in c-Fos expression; in particular, a strong response to stress was found in hippocampus and cortex.

In the hippocampus of control animals, c-fos immunoreactive cells were almost undetectable (consistent with Hughes et al., 1992). Restraint stress led to a reliable increase in the number of Fos-positive cells. It is interesting that the localization of these responsive neurons was not distributed evenly across the CA3 area and the dentate gyrus. For example, Fos immunoreactive cells concentrated predominantly not in the septal, but in the temporal pole of hippocampus. It is possible that this distribution reflects a neuroanatomical and functional difference between these two parts of hippocampus, resulting in higher excitability of the temporal region (Grimes et al., 1989; Lee et al., 1990). Consistent with the increase in c-Fos protein expression observed by immunohistochemistry, the level of c-fos mRNA was found significantly increased when total RNA of the hippocampus was assayed.

In the neocortex the number of c-Fos-positive cells and the level of c-fos mRNA was low in control animals but significantly increased in animals exposed to restraint stress. As detected by immunohistochemistry, this induction was not equally distributed throughout cortex, but was higher in cingulate and piriform areas consistent with reports of Sharp et al. (1991), Giovanelli et al. (1992), and Stone et al. (1993).

In agreement with the studies of Le et al. (1990, 1992) we did not observe any significant effects of the alcohol treatment alone on levels of c-fos mRNA or c-Fos protein in hippocampus and in cortex. Even stressful doses of alcohol resulting in high blood alcohol levels and elevation of circulating corticosterone failed to induce c-fos expression in hippocampus and cortex. These data demonstrate a dissociation of the adrenal cortical response and c-fos expression in rat brain and supports the position that c-fos expression and its induction in response to certain physiological stimuli in hippocampus, cortex, and hypothalamus is not secondary to the activation of adrenal response and release of corticosteroids (Brown and Sawchenko, 1993; Melia et al., 1994).

Although there appeared to be no direct effects of alcohol on 
basal IEG expression in cortex and hippocampus, alcohol strongly attenuated the induction of $\mathrm{c}$-fos expression in hippocampus in response to restraint stress. This effect was clearly seen by immunohistochemical analysis in the dentate gyrus of the temporal pole of hippocampus and in the CA 3 region, and was significant at the RNA level when the samples from the entire hippocampus were analyzed. In cortex, the picture that emerges appears more complex. Alcohol decreased the number of stress-induced c-Fosexpressing cells in cingulate cortex and, to a lesser extend, in piriform cortex, but not in the somatosensory cortex. When analyzed at the level of RNA, the attenuating effect of alcohol on stress-induced c-fos expression was not significant statistically, probably because a dissection of the entire cortex was used for RNA isolation.

Our findings strongly support the notion that alcohol in moderate doses does not act as a nonspecific depressant, but rather selectively affects only certain sensitive neurons. Recently, Le et al. (1992) demonstrated a receptor-specific effect of alcohol on seizure-induced $c$-fos expression in rat brain: only NMDA and GABA, but not kainic acid or caffeine, mediated induction was affected by alcohol. In the present experiments where $c$-fos was induced by a mainly psychological stressor, we were ablc to demonstrate that the effect of alcohol can also be population specific. The specificity of the neuronal populations responding to alcohol probably reflects the receptor specificity of these cells (Ticku et al., 1986; Lovinger et al., 1989; Hegarty and Vogel, 1993). The mechanism through which this receptor specificity is reached has yet to be characterized, especially regarding the possibility that these selective effects of alcohol can be mediated through neurons of other brain regions such as ventral tegmental area or locus coeruleus. For example, ethanol has recently been shown to inhibit facilitation of dentate gyrus responses to stimulation of dopaminergic inputs from the ventral tegmental area (Criado et al., 1994).

Our results also show that there is a difference in response to restraint stress and alcohol within the series of IEGs studied. This was not unexpected, since these IEGs differ in the mechanisms leading to their activation (Bartcl ct al., 1989; Auwerx et al., 1990) and in the general distribution of their activity throughout different brain regions (Wisden et al., 1990; Mellstrom et al., 1991). Consistent with observations showing parallel regulation of c-fos and jun-B by behavioral stimuli (Kornhauser et al., 1992; Rosen et al., 1992), we observed that these genes were, indeed, coactivated after stress in cortex and hippocampus. However, stress induction of jun-B in hippocampus appeared to be less sensitive to alcohol treatment than induction of c-fos. jun-D expression was also increased after restraint stress in both cortex and hippocampus, and this induction was not significantly attenuated by alcohol. In contrast, c-jun was induced by restraint stress in cortex but not in hippocampus and, like jun-D, was not sensitive to alcohol. Assuming that some of the activated IEGs were expressed in the same cells, it is likely that the primarily psychological stressor used in our experiments led to an increase in various Fos-Jun heteromers. The specific suppression of the c-Fos response by prior alcohol exposure suggests the interesting possibility that alcohol may lead to a relative deficiency of c-Fos, thus increasing the likelihood of Jun-Jun complexes in hippocampus. This may perturb the normal physiological cascade of responses to the stressor by reducing the efficiency of transcriptional activation or by redirecting AP-1 activation to other target genes. Clearly, studies closely evaluating the time course and cell specific expression of individual IEGs, in particular, members of the jun family, together with identification of genes targeted for these IEGs, will be necessary to fully evaluate this hypothesis.

In summary, using c-fos expression as a marker of neural activity we have demonstrated that alcohol can differentially alter stress response in selected neuronal populations including hippocampus and cingulate cortex. This interaction differentially affects expression of IEGs by principally suppressing the induction of expression of c-Fos in the CA3 region and dentate gyrus. It is intriguing to consider that this effect of alcohol on hippocampus, the primary structure participating in the formation of declarative memory and cognitive functions (cf. Squire, 1992), might reflect the anxiolytic effects of alcohol. However, it is not yet clear whether the attenuation of stress-induced IEG response in hippocampus reflects the cause of "tension reduction" by alcohol or is an epiphenomenon of the effects of alcohol on other CNS circuitry, in example, through catecholaminergic or dopaminergic transmission. Further investigations will be necessary to fully distinguish between these potential underlying mechanisms.

\section{References}

Anokhin KV, Ryabinin AE (1991) c-fos gene expression in the mouse brain after active avoidance learning. Abstr. 14th Ann. Meet. Eur. Neurosci. Assoc. Eur J Neurosci [Suppl] 4:62.

Anokhin KV, Ryabinin AE (1993) Expression of c-fos and c-jun genes in the neocortex and hippocampus of mice after passive avoidance learning. Int J Memory 1:67-70.

Arnold FJ, De Lucas Bueno M, Shriers H, Hancock DC, Evan GI, Herbert J (1992) Expression of c-fos in regions of the basal limbic forebrain following intracerebroventricular corticotropin-releasing factor in unstressed or stressed male rats. Neuroscience 51:377-390.

Auwerx J, Staels B, Sassoni-Corsi P (1990) Coupled and uncoupled induction of fos and jun transcription by different second messengers in cells of hemopoetic origin. Nucleic Acids Res 18:221-228.

Bartel DP, Sheng M, Lau LF, Greenberg ME (1989) Growth factors and membrane depolarization activate distinct programs of early response gene expression: dissociation of fos and jun function. Genes Dev 3:304-313.

Bing G, Stone EA, Zhang Y, Filer D (1992) Immunohistochemical studies of noradrenergic-induced expression of c-fos in the rat CNS. Brain Res 592:57-62.

Birder LA, de Groat WC (1992) The effect of glutamate antagonists on c-fos expression induced by irritation of the lower urinary tract. Brain Res 580:115-120.

Brown ER, Sawchenko PE (1993) Adrenalectomy presents a dynamic stimulatory challenge to parvocellular neurosecretory neurons. Soc Neurosci Abstr 19:760.

Campeau S, Hayward M, Hope BT, Rosen JB, Nestler EJ, Davis M (1991) Induction of the c-fos proto-oncogene in rat amygdala during unconditioned and conditioned fear. Brain Res 565:349-352.

Cecatelli S, Villar MJ, Goldstein M, Hokfelt T (1989) Expression of c-fos immunoreactivity in transmitter-characterized neurons after stress. Proc Natl Acad Sci USA 86:9569-9573.

Chomczynski P, Sacchi N (1987) Single step method of RNA isolation by acid guanidinium thiocyanate-phenol-chlorophorm extraction. Anal Biochem 162:156-159.

Conger JJ (1956) Alcoholism; Theory, problem and challenge. II Reinforcement theory and the dynamics of alcoholism. Q J Stud Alcohol 17:296-305.

Covenas R, de Leon M, Cintra A, Bjelke B, Gustafsson JA, Fuxe K (1993) Coexistence of c-fos and glucocorticoid receptor immunoreactivities in the CRF immunoreactive neurons of the paraventricular hypothalamic nucleus of the rat aftcr acutc immobilization stress. Neurosci Lett 149:149-152.

Criado JR, Steffenson SC, Henriksen SJ (1994) Ethanol acts via ventral tegmental area to influence hippocampal physiology. Synapse 17:84 91.

Curran T, Franza BR Jr (1988) Fos and Jun: the AP-1 connection. Cell 55:395-397.

Curran T, Morgan JI (1987) Memories of fos. Bioessays 7:255-258. 
Dave JR, Tabakoff B, Hoffman PL (19xx) Ethanol withdrawal seizures produce increased c-fos mRNA in mouse brain. Mol Pharmacol 37: 367-371.

Dragunow M, Robertson HA (1987) Generalized seizures induce c-fos protein(s) in mammalian neurons. Neurosci Lett 82:157-161.

Dragunow M, Currie RW, Faul TLM, Robertson HA, Jansen K (1989) Immediate early genes, kindling and long-term potentiation. Neurosci Biobehav Rev 13:301-313.

Duncan GE, Johnson KB, Breese GR (1993) Topographic patterns of brain activity in response to swim stress: assessment by 2-deoxyglucose uptake and expression of Fos-like immunoreactivity. J Neurosci 13: 3932-3943.

Ellis FW (1966) Effect of cthanol on plasma corticostcronc lcvels. J Pharmacol Exp Ther 153:121-128.

Engel J,Liljerquist S (1983) The involvement of different central neurotransmitters in mediating stimulatory and sedative effects of ethanol. In: Stress and alcohol use (Pohorecky LA, Brick J, eds). New York: Elsevier.

Giovanelli L, Shiromani PJ, Jirikowski GF, Bloom FE (1990) Oxytocin neurons in the rat hypothalamus exhibit c-fos immunoreactivity upon osmotic stress. Brain Res 531:299-303.

Grimes LM, Earnhardt TS, Mitchel CL Tilson HA, Hong J-S (1989) Granule cells in ventral, but not dorsal, dentate gyrus are essential for kainic acid-induced wet dog shakes. Brain Res 514:167-170.

Hegarty AA, Vogel WH (1993) Modulation of the stress response in the rat frontal cortex. Pharmacol Biochem Behav 45:327-334.

Honkaniemi J (1992) Colocalization of peptidc- and tyrosinc hydroxylase-like immunoreactivities with Fos-immunoreactive neurons in rat central amygdaloid nucleus after immobilization stress. Brain Res 598:107-113.

Hughes P, Lawlor P, Dragunow M (1992) Basal expression of Fos, Fos-related and Krox 24 proteins in rat hippocampus. Mol Brain Res 13:355-357.

Koob GF, Thatcher-Britton K, Britton DR, Roberts DCS, Bloom FE (1984) Destruction of the locus coeruleus of the dorsal NE bundle does not alter the release of punished responding by ethanol and chlordiazepoxide. Physiol Behav 33:479-485.

Kornhauser JM, Nelson DE, Mayo K, Takahashi JS (1992) Regulation of $j u n-\mathrm{B}$ messenger RNA and AP- 1 activity by light and a circadian clock. Science 255:1581-1584.

Kruijer W, Schubert D, Verma IM (1985) Induction of the protooncogene fos by nerve growth factor. Proc Natl Acad Sci USA 82: $7330-7334$

Le F, Wilce P, Cassady AI, Hume DA, Shanley BC (1990) Acute administration of ethanol suppresses pentylenetetrazole-induced c-fos expression in rat brain. Neurosci Lett 120:271-274.

Le F, Wilce PA, Hume DA, Shanley BC (1992) Involvement of $\gamma$-aminobutyric acid and $N$-methyl-D-aspartate receptors in the inhibitory effect of ethanol on pentylenetetrazole-induced c-fos expression in rat brain. J Neurochem 59:1309-1315.

Lee PHK, Xie C-W, Lewis DV, Wilson WA, Mitchell CL Hong J-S (1990) Opioid-induced epileptiform bursting in hippocampal slices: higher susceptibility in ventral than dorsal hippocampus. J Pharmacol Exp Ther 253:545-551.

Lovinger DM, White G, Weight FF (1990) NMDA receptor-mediated synaptic excitation selectively inhibited by ethanol in hippocampal slice from adult rat. J Neurosci 10:1372-1379.

Maleeva NE, Ivolgina GL, Anokhin KV, Limborskaya SA (1989) Analysis of the expression of the c-fos protooncogene in the rat cerebral cortex during learning. Genetika 25:1119-1121.

Masserman JH, Yum KS (1946) An analysis of the influence of alcohol on experimental neuroses in cats. Psychosom Med 8:36-52.

Melia KR, Ryabinin AE, Schroeder R, Wilson MC, Bloom FE (1994) Induction and habituation of immediate early gene expression in rat brain by acute and repeated restraint stress. $\mathbf{J}$ Neurosci, in press.

Mellstrom B, Achaval M, Montero D, Naranjo JR, Sassone-Corsi X (1991) Differential expression of the jun family members in rat brain.

Morgan JI, Curran T (1991) Stimulus-transcription coupling in the nervous system: involvement of the inducible proto-oncogenes fos and jun. Annu Rev Neurosci 14:421-451.
Morgan JI, Cohen DR, Hempstead JL, Curran T (1987) Mapping patterns of c-fos expression in the central nervous system after seizure. Science 236:192-197.

Nakabeppu Y, Ryder K, Nathans D (1988) DNA binding activities of three murine Jun proteins: stimulation by Fos. Cell 55:907-915.

Nikolaev E, Kaminska B, Tischmeyer W, Matthies H, Kaczmarek L (1992) Induction of expression of genes encoding transcription factors in the rat brain elicited by behavioral training. Brain Res Bull 28:479-484.

Patel VA, Pohorecky LA (1988) Interaction of stress and ethanol: effect of beta-endorphin and catecholamines. Alcohol Clin Exp Res 12:785788.

Pezzone MA, Lec W-S, Hoffman GE, Rabin BS (1992) Induction of c-Fos immunoreactivity in the rat forebrain by conditioned and unconditioned aversive stimuli. Brain Res 597:41-50.

Pohorecky LA (1990) Interaction of ethanol and stress: research with experimental animals-an update. Alcohol 25:263-276.

Rivest S, Torres G, Rivier C (1992) Differential effects of central and peripheral injection of interleukin- $1 \beta$ on brain $c$-fos expression and neuroendocrine function. Brain Res 587:13-23.

Rosen KM, McCormack MA, Villa-Komaroff L, Mower GD (1992) Brief visual experience induces immediate early gene expression in the cat visual cortex. Proc Natl Acad Sci USA 89:5437-5441.

Saffen DW, Cole AJ, Worley PF, Christy A, Ryder D, Baraban JM (1988) Convulsant-induced increase in transcription factor messenger RNAs in rat brain. Proc Natl Acad Sci USA 85:7795-7799.

Sagar SM, Sharp FR, Curran T (1988) Expression of c-fos protein in brain: metabolic mapping at cellular level. Science 240:1328-1331.

Sambrook J, Fritsch EF, Maniatis T (1992) Molecular cloning. A laboratory manual. Cold Spring Harbor, NY: Cold Spring Harbor Laboratory.

Schreiber SS, Tocco G, Shors TJ, Thompson RF (1991) Activation of immediate early genes after acute stress. Mol Neurosci 2:17-20.

Sharp FR, Sagar SM, Hicks K, Lowenstein D, Hisanaga K (1991) cfos mRNA, Fos and Fos-related antigen induction by hypertonic saline and stress. J Neurosci 11:2321-2331.

Sheng M, Greenberg ME (1990) The regulation and function of c-fos and other immediate early genes in the nervous system. Neuron 4:474 485

Smith MA, Banerjee S, Gold PW, Glowa J (1992) Induction of c-fos $m R N A$ in rat brain by conditioned and unconditioned stressors. Brain Res 578:135-141.

Sonnenberg JL, Macgregor-Lron PF, Curran T, Morgan JI (1989) Dynamic alterations occur in the levels and composition of transcription factor AP-1 complexes after seizure. Neuron 3:359-365.

Squire LR (1992) Memory and the hippocampus: a synthesis from findings with rats, monkeys and humans. Psychol Rev 99:195-231.

Stone EA, Zhang Y, John S, Filer D, Bing G (1993) Effect of locus coeruleus lesion on c-fos expression in the cerebral cortex caused by yohimbine injection or stress. Brain Res 603:181-185.

Ticku MK, Burch TP, Davis WC (1983) The interactions of ethanol with benzodiazepine-GABA receptor-ionophore complex. Pharmacol Biochem Behav 18[Suppl 1]:15-18.

Tischmeyer W, Kaczmarek L, Strauss M, Jork R, Matthies H (1990) Accumulation of c-fos mRNA in rat hippocampus during brightness discrimination. Behav Neural Biol 54:165-171.

Vogel WH, Deturck KH (1983) Effect of ethanol on plasma and brain cathecholamine levels in stressed and unstressed rats. In: Stress and alcohol use (Pohorecky LA, Brick J, eds). New York: Elsevier.

Wisden W, Errington ML, Williams S, Dunnett SB, Waters C, Hitchcock D, Evan J, Bliss TVP, Hunt SP (1990) Differential expression of immediate early genes in the hippocampus and spinal cord. Neuron 4:603-614.

Zerial M, Toschi L, Ryseck R-P, Schuermann M, Muller R, Bravo R (1989) The product of a novel growth factor activated gene, fos $\mathrm{B}$ interacts with Jun proteins enhancing their binding activity. EMBO J 8:805-813 